Cite this: New J. Chem., 2014, 38,3227

Received (in Montpellier, France) 25th April 2014,

Accepted 7th May 2014

DOI: $10.1039 / c 4 n j 00651 \mathrm{~h}$

www.rsc.org/njc

\section{2-Diphenylaminothiophene as the donor of porphyrin sensitizers for dye-sensitized solar cells†}

\author{
Yueqiang Wang, ${ }^{a} \mathrm{Lu} \mathrm{Xu}^{\mathrm{a}}$ Xiaodong Wei, ${ }^{\mathrm{a}}$ Xin $\mathrm{Li}^{\mathrm{b}}{ }^{\mathrm{b}}$ Hans Ågren, ${ }^{\mathrm{b}}$ Wenjun $\mathrm{Wu}^{\mathrm{a}}$ and \\ Yongshu Xie ${ }^{* a}$
}

Four novel $D-\pi-A$ porphyrin dyes (YQ1-YQ4) with 2-diphenylaminothiophene attached at the mesoposition as the electron donor have been synthesized and used as the sensitizers for dye sensitized solar cells (DSSCs). 4-Ethynylbenzoic acid and 2-cyanoacrylic acid were incorporated as the anchoring moieties in YQ1, and YQ2-YQ4, respectively. Due to the extended conjugation size, the absorption spectra of YQ2-YQ4 showed Soret band maxima in the range of 447-468 nm, which is red shifted as compared to that of $446 \mathrm{~nm}$ for YQ1. Furthermore, in comparison with most reported porphyrin dyes with similar structures, YQ1-YQ4 demonstrate obviously red-shifted absorption maxima and broadened Soret bands, indicating that these porphyrin dyes may be developed as promising DSSC sensitizers. The electrochemical studies and DFT calculations indicated that all the four dyes were capable of serving as DSSC sensitizers. Thus, DSSCs were fabricated based on these dyes. The cells based on YQ4 showed the power conversion efficiency of $5.00 \%$, which is higher than those of $4.23 \%$ and $4.38 \%$ for YQ2 and YQ3, respectively. This observation may be attributed to the suppression of the dye aggregation by the hexyl group attached to the thienyl ring of YQ4. On the other hand, YQ2-YQ4 demonstrated lower efficiencies compared with YQ1, which may be ascribed to the floppy structures of the cyanoacrylic acid-based porphyrins that provide free space for charge recombination. As a result, the DSSCs based on YQ1 exhibited the highest efficiency of $6.01 \%$. This work demonstrates that the introduction of 2-diphenylaminothiophene into a porphyrin framework can obviously red-shift and broaden the absorption bands of the porphyrin dyes, resulting in high solar cell efficiencies. Hence, the introduction of 2-diphenylaminothiophene as the electron donor may be promising for the design of efficient porphyrin-based DSSC sensitizers.

\section{Introduction}

Dye-sensitized solar cells (DSSCs) have been demonstrated to be promising in utilizing the solar energy. ${ }^{1}$ In the past decade, many efforts have been devoted to the development of efficient DSSC sensitizers. ${ }^{2}$ In this respect, many ruthenium-based sensitizers have been successfully developed. ${ }^{3}$ On the other hand, increasing interests have been focused on the development of new efficient organic sensitizers because of their advantages of low cost, high molar absorption coefficients, and facile modulation of the

\footnotetext{
${ }^{a}$ Key Laboratory for Advanced Materials and Institute of Fine Chemicals, Shanghai Key Laboratory of Functional Materials Chemistry,

East China University of Science and Technology, Shanghai, P. R. China. E-mail: yshxie@ecust.edu.cn; Fax: +86-21-6425-2758; Tel: +86-21-6425-0772

${ }^{b}$ Department of Theoretical Chemistry and Biology,

School of Biotechnology KTH Royal Institute of Technology, Stockholm, Sweden $\dagger$ Electronic supplementary information (ESI) available: ${ }^{1} \mathrm{H}$ NMR, and MALDITOF spectra of intermediates and target porphyrins (Fig. S1 to S24). See DOI: 10.1039/c4nj00651h
}

properties by the modification of the molecular structures. ${ }^{4}$ As is well known, the donor- $\pi$-acceptor $(\mathrm{D}-\pi-\mathrm{A})$ frameworks are the most commonly adopted for organic sensitizers. ${ }^{5}$ In this respect, we have reported various dyes incorporating indoline and isophorone units. ${ }^{6}$

Among the organic dyes, porphyrins have been considered to be promising sensitizers inspired by their important roles in the natural photosynthesis system. ${ }^{7}$ They have strongly absorbing Soret bands (400-450 nm) and moderately absorbing Q-bands (550-600 nm) from the visible to the near-IR region. ${ }^{8}$ Thus, numerous porphyrins have been synthesized and used as DSSC sensitizers. ${ }^{9}$ In this respect, the highest efficiency of $13.0 \%$ achieved for DSSCs has been reported by Grätzel and co-workers for a porphyrin dye SM315, using 2,1,3-benzothiadiazole as an electron accepting unit, which is conjugated with the anchoring benzoic acid group. ${ }^{10}$

The electron rich thienyl group has been widely utilized in porphyrin-based sensitizers to enhance and red-shift the absorption of the dyes. ${ }^{12}$ Based on our previous work on the porphyrin 

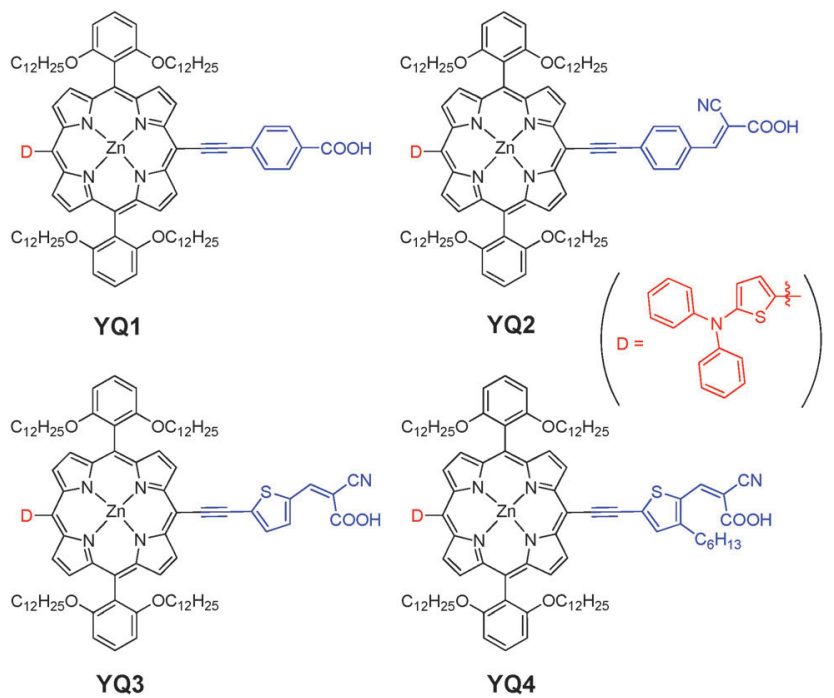

Scheme 1 Molecular structures of the porphyrin sensitizers.

dyes utilizing triphenylamine and carbazole as the donors, ${ }^{11}$ herein, 2-diphenylaminothiophene was introduced into the porphyrin framework as the donor, with the thienyl group used to increase the electron donating character. Thus, we synthesized a series of novel porphyrin sensitizers (YQ1-YQ4, Scheme 1).

The planar structural feature of the porphyrins may facilitate the formation of aggregates. Thus, the porphyrins were all enveloped with alkoxyl chains to decrease the dye aggregation and to retard the charge recombination process. ${ }^{13}$ In addition, various acceptors were employed (Scheme 1) to further optimize the dye performance. Thus, YQ1-YQ4 were synthesized and utilized as sensitizers to fabricate DSSCs, and the results indicated that YQ1 exhibited the highest power conversion efficiency of $6.01 \%$, which is higher than those for our previously reported porphyrin dyes containing triphenylamine donors. ${ }^{11 a}$

\section{Experimental section}

\section{Materials and reagents}

All reagents and solvents were obtained from commercial sources and used without further purification unless otherwise noted. THF was dried over $4 \AA$ molecular sieves, and distilled under nitrogen from sodium benzophenone prior to use. Tetrabutylammonium hexafluorophosphate $\left(\mathrm{TBAPF}_{6}\right)$ was vacuum-dried for $48 \mathrm{~h}$. The transparent FTO conducting glass (fluorine-doped $\mathrm{SnO}_{2}$, transmission $>90 \%$ in the visible range, a sheet resistance of $15 \Omega$ per square) and the $\mathrm{TiO}_{2}$ paste were purchased from Geao Science and Educational Co. Ltd. The FTO conducting glass was washed with a detergent solution, deionized water, ethanol, and acetone successively under ultrasonication for 20 min prior to use. Dibromoporphyrin 1 and 3-hexyl-5-ethynylthiophene-2-carbaldehyde were prepared according to the reported procedures. ${ }^{13 c, 14}$

\section{Equipment and apparatus}

${ }^{1} \mathrm{H}$ NMR and ${ }^{13} \mathrm{C}$ NMR spectra were obtained using a Bruker AM 400 or a $500 \mathrm{MHz}$ spectrometer at $298 \mathrm{~K}$ with tetramethylsilane
(TMS) as the internal standard. Matrix-assisted laser desorption/ ionization time-of-flight mass spectrometry (MALDI-TOF-MS) was measured using a Shimadzu-Kratos model Axima CFR+ mass spectrometer with dithranol as the matrix. UV-Vis absorption spectra were recorded on a Varian Cary 100 spectrophotometer and fluorescence spectra were recorded on a Varian Cray Eclipse fluorescence spectrophotometer. The cyclic voltammograms of the dyes were obtained in acetonitrile with a Versastat II electrochemical workstation (Princeton Applied Research) using 0.1 M $\mathrm{TBAPF}_{6}$ (Aldrich) as the supporting electrolyte, the sensitizer attached to a nanocrystalline $\mathrm{TiO}_{2}$ film deposited on the conducting FTO glass as the working electrode, a platinum wire as the counter electrode, and a regular calomel electrode in saturated $\mathrm{KCl}$ solution as the reference electrode. The scan rate was $100 \mathrm{mV} \mathrm{s}^{-1}$.

Photovoltaic measurements were performed by employing an AM 1.5 solar simulator equipped with a $300 \mathrm{~W}$ xenon lamp (model no. 91160, Oriel). The power of the simulated light was calibrated to $100 \mathrm{~mW} \mathrm{~cm}^{-2}$ using a Newport Oriel PV reference cell system (model $91150 \mathrm{~V}$ ). $I-V$ curves were obtained by applying an external bias to the cell and measuring the generated photocurrent using a model 2400 source meter (Keithley Instruments, Inc. USA). The voltage step and delay time of the photocurrent were $10 \mathrm{mV}$ and $40 \mathrm{~ms}$, respectively. Action spectra of the incident monochromatic photon-to-electron conversion efficiency (IPCE) of the solar cells were obtained using a Newport-74125 system (Newport Instruments). The intensity of monochromatic light was measured using a Si detector (Newport-71640). The electrochemical impedance spectroscopy (EIS) measurements of all the DSSCs were performed using a Zahner IM6e Impedance Analyzer (ZAHNER-Elektrik GmbH \& CoKG, Kronach, Germany), with the frequency range of $0.1 \mathrm{~Hz}-100 \mathrm{kHz}$ and the alternative signal of $10 \mathrm{mV}$.

\section{Fabrication of the solar cells}

The procedure for preparation of $\mathrm{TiO}_{2}$ electrodes and fabrication of the sealed cells for photovoltaic measurements was adapted from that reported by Grätzel and co-workers. ${ }^{15}$ A screen-printed double layer of $\mathrm{TiO}_{2}$ particles was used as the photoelectrode. The detailed procedure was reported in our previous work. ${ }^{11}$ The films were then immersed into a $0.2 \mathrm{mM}$ solution of the dyes in a mixture of tetrahydrofuran (THF) and ethanol (EtOH) (a volume ratio of 1:4) for $10 \mathrm{~h}$ at room temperature. The counter electrode was also prepared according to the procedure reported in our previous work. ${ }^{11}$ Finally, the DSSCs were assembled, with the electrolyte solution containing $0.1 \mathrm{M} \mathrm{LiI}, 0.05 \mathrm{M} \mathrm{I}_{2}, 0.6 \mathrm{M}$ 1-methyl-3-propylimidazolium iodide (PMII), and 0.5 M 4-tert-butylpyridine (TBP) in acetonitrile.

\section{Syntheses of the dyes}

The procedures for the syntheses of $\mathbf{3 a - 3 \mathbf { d }}$ are described in the ESI. $\dagger$

YQ1: A mixture of the porphyrin carboxylate $3 a(30 \mathrm{mg}$, $0.018 \mathrm{mmol})$ and LiOH$\cdot \mathrm{H}_{2} \mathrm{O}(30 \mathrm{mg}, 0.72 \mathrm{mmol})$ in THF $(30 \mathrm{~mL})$ and $\mathrm{H}_{2} \mathrm{O}(4 \mathrm{~mL})$ was refluxed for $12 \mathrm{~h}$ under nitrogen. Then, the solvent was removed in vacuo. The residue was dissolved in THF and the precipitate was filtered off. The filtrate was concentrated 
in vacuo to afford the crude product, which was purified by column chromatography on silica gel to give the product as a green powder (25 mg, yield 85\%). ${ }^{1} \mathrm{H}$ NMR $\left(\mathrm{CDCl}_{3}: \mathrm{DMSO}_{6}=\right.$ $1: 2,400 \mathrm{MHz}, \mathrm{ppm}): \delta 0.27-0.35(\mathrm{~m}, 8 \mathrm{H}), 0.52-0.56(\mathrm{~m}, 16 \mathrm{H})$, 0.66-0.81 (m, 20H), 0.84-1.12 (m, 40H), 1.13-1.20 (m, 8H), 3.85 $(\mathrm{t}, J=6.4 \mathrm{~Hz}, 8 \mathrm{H}), 7.05-7.12(\mathrm{~m}, 7 \mathrm{H}), 7.35-7.43(\mathrm{~m}, 8 \mathrm{H}), 7.59$ (d, $J=3.6 \mathrm{~Hz}, 1 \mathrm{H}$, thienyl), $7.71(\mathrm{t}, J=8.4 \mathrm{~Hz}, 2 \mathrm{H}$, phenyl), 8.07 (d, $J=7.6 \mathrm{~Hz}, 2 \mathrm{H}$, phenyl), 8.17 (d, $J=8.0 \mathrm{~Hz}, 2 \mathrm{H}$, phenyl), 8.68 (d, $J=4.4 \mathrm{~Hz}, 2 \mathrm{H}$, pyrrolic), 8.75 (d, $J=4.0 \mathrm{~Hz}, 2 \mathrm{H}$, pyrrolic), 9.01 (d, $J=4.4 \mathrm{~Hz}, 2 \mathrm{H}$, pyrrolic), 9.60 (d, $J=4.4 \mathrm{~Hz}, 2 \mathrm{H}$, pyrrolic). MS (MALDI-TOF, $\mathrm{m} / \mathrm{z}$ ): [M] calcd for $\mathrm{C}_{105} \mathrm{H}_{131} \mathrm{~N}_{5} \mathrm{O}_{6} \mathrm{SZn}, 1653.91$; found, 1653.69. IR ( $\mathrm{KBr}$ pellet, $\left.\mathrm{cm}^{-1}\right)$ : 2922(s), 2852(m), 2183(w), 2029(w), 1958(m), 1660(m), 1618(s), 1602(m), 1494(w), 1455(m), 1272(w), 1241(w), 1100(m), 994(m), 789(w).

YQ2: A mixture of $\mathbf{3 b}(30 \mathrm{mg}, 0.018 \mathrm{mmol})$ and cyanoacetic acid $(6 \mathrm{mg}, 0.073 \mathrm{mmol})$ in acetonitrile $(10 \mathrm{~mL})$ was heated to reflux in the presence of piperidine $(0.5 \mathrm{~mL})$ for $10 \mathrm{~h}$ under nitrogen. After cooling, the mixture was diluted with $\mathrm{CH}_{2} \mathrm{Cl}_{2}$ $(50 \mathrm{~mL})$, washed with water and brine, dried over $\mathrm{Na}_{2} \mathrm{SO}_{4}$, and evaporated under reduced pressure. The crude product was purified by column chromatography on silica gel to yield the product as a green powder $(20 \mathrm{mg}$, yield $65 \%) .{ }^{1} \mathrm{H} \mathrm{NMR}\left(\mathrm{CDCl}_{3}\right.$ : DMSO- $\left.d_{6}=1: 2,500 \mathrm{MHz}, \mathrm{ppm}\right): \delta 0.43-0.49(\mathrm{~m}, 8 \mathrm{H}), 0.60-0.67$ (m, 16H), 0.77-0.84 (m, 20H), 0.87-1.12 (m, 40H), 1.14-1.21 $(\mathrm{m}, 8 \mathrm{H}), 3.84(\mathrm{t}, J=6.0 \mathrm{~Hz}, 8 \mathrm{H}), 7.01(\mathrm{~d}, J=8.5 \mathrm{~Hz}, 2 \mathrm{H}$, phenyl), $7.07-7.11(\mathrm{~m}, 3 \mathrm{H}), 7.36-7.42(\mathrm{~m}, 8 \mathrm{H}), 7.58(\mathrm{~d}, J=2.5 \mathrm{~Hz}, 1 \mathrm{H}$, thienyl), $7.69(\mathrm{t}, J=8.0 \mathrm{~Hz}, 2 \mathrm{H}$, phenyl), $8.08(\mathrm{~d}, J=8.0 \mathrm{~Hz}, 2 \mathrm{H}$, phenyl), 8.18 (d, $J=8.5 \mathrm{~Hz}, 2 \mathrm{H}$, phenyl), 8.33 (s, 1H), 8.74 (d, $J=4.5 \mathrm{~Hz}, 2 \mathrm{H}$, pyrrolic), 8.83 (d, $J=5.0 \mathrm{~Hz}, 2 \mathrm{H}$, pyrrolic), 9.06 (d, $J=4.5 \mathrm{~Hz}, 2 \mathrm{H}$, pyrrolic), 9.60 (d, $J=5.0 \mathrm{~Hz}, 2 \mathrm{H}$, pyrrolic). MS (MALDI-TOF, $m / z$ ): [M] calcd for $\mathrm{C}_{108} \mathrm{H}_{132} \mathrm{~N}_{6} \mathrm{O}_{6} \mathrm{SZn}, 1704.92$; found, 1705.46. IR (KBr pellet, $\mathrm{cm}^{-1}$ ): 3357(br), 2922(s), 2851(s), 2180(w), 2027(w), 1959(m), 1723(m), 1658(m), 1632(s), 1467(m), 1410(m), 1181(w), 1139(w), 1175(w), 733(w).

YQ3: It was prepared according to the procedure same as that for Y2, except that $3 \mathbf{c}(30 \mathrm{mg}, 0.018 \mathrm{mmol})$ was used instead of 3b. Yield: $21 \mathrm{mg}, 68 \% .{ }^{1} \mathrm{H} \mathrm{NMR}\left(\mathrm{CDCl}_{3}: \mathrm{DMSO}_{6}=\right.$ $1: 2,500 \mathrm{MHz}, \mathrm{ppm}): \delta 0.23-0.30(\mathrm{~m}, 8 \mathrm{H}), 0.39-0.50(\mathrm{~m}, 16 \mathrm{H})$, 0.67-0.78 (m, 20H), 0.85-1.06 (m, 40H), 1.08-1.14 (m, 8H), 3.80 (t, $J=6.0 \mathrm{~Hz}, 8 \mathrm{H}), 7.02(\mathrm{~d}, J=8.5 \mathrm{~Hz}, 2 \mathrm{H}$, phenyl), 7.05-7.08 $(\mathrm{m}, 3 \mathrm{H}), 7.31-7.38(\mathrm{~m}, 8 \mathrm{H}), 7.55(\mathrm{~d}, J=3.5 \mathrm{~Hz}, 1 \mathrm{H}$, thienyl), 7.66 (t, $J=8.5 \mathrm{~Hz}, 2 \mathrm{H}$, phenyl), 7.73 (d, $J=4.0 \mathrm{~Hz}, 1 \mathrm{H}$, thienyl), 7.81 (d, $J=4.0 \mathrm{~Hz}, 1 \mathrm{H}$, thienyl), $8.20(\mathrm{~s}, 1 \mathrm{H}), 8.62(\mathrm{~d}, J=4.5 \mathrm{~Hz}, 2 \mathrm{H}$, pyrrolic), 8.71 (d, $J=4.5 \mathrm{~Hz}, 2 \mathrm{H}$, pyrrolic), 8.97 (d, $J=4.5 \mathrm{~Hz}, 2 \mathrm{H}$, pyrrolic), 9.44 (d, $J=4.5 \mathrm{~Hz}, 2 \mathrm{H}$, pyrrolic). MS (MALDI-TOF, $m / z):[\mathrm{M}]$ calcd for $\mathrm{C}_{106} \mathrm{H}_{130} \mathrm{~N}_{6} \mathrm{O}_{6} \mathrm{~S}_{2} \mathrm{Zn}, 1710.88$; found, 1710.92 . IR (KBr pellet, $\left.\mathrm{cm}^{-1}\right)$ : 3358(br), 2922(s), 2851(s), 2179(w), 2030(w), 1958(m), 1659(s), 1632(s), 1468(w), 1455(s), 1410(w), 1178(w), 1099(w), 995(w), 790(w), 717(w).

YQ4: It was prepared according to the procedure same as that for Y2, except that 3d (32 $\mathrm{mg}, 0.018 \mathrm{mmol}$ ) was used instead of 3b. Yield: $21 \mathrm{mg}, 64 \% .{ }^{1} \mathrm{H} \mathrm{NMR}\left(\mathrm{CDCl}_{3}: \mathrm{DMSO}^{-} d_{6}=\right.$ $1: 2,500 \mathrm{MHz}, \mathrm{ppm}): \delta 0.37-0.45(\mathrm{~m}, 8 \mathrm{H}), 0.51-0.64(\mathrm{~m}, 16 \mathrm{H})$, 0.74-0.86 (m, 20H), 0.88-1.12 (m, 43H), 1.16-1.22 (m, 8H), 1.65-1.70 (m, 4H), 2.00-2.07 (m, 4H), $3.26(\mathrm{t}, J=7.5 \mathrm{~Hz}, 2 \mathrm{H})$, $3.88(\mathrm{t}, J=5.5 \mathrm{~Hz}, 8 \mathrm{H}), 7.05-7.14(\mathrm{~m}, 7 \mathrm{H}), 7.34-7.45(\mathrm{~m}, 8 \mathrm{H})$, $7.62(\mathrm{~s}, 1 \mathrm{H}$, thienyl), $7.73(\mathrm{t}, J=8.0 \mathrm{~Hz}, 2 \mathrm{H}$, phenyl), $8.27(\mathrm{~s}, 1 \mathrm{H})$, $8.73(\mathrm{~d}, J=5.0 \mathrm{~Hz}, 2 \mathrm{H}$, pyrrolic), 8.79 (d, $J=5.0 \mathrm{~Hz}, 2 \mathrm{H}$, pyrrolic), 9.05 (d, $J=4.5 \mathrm{~Hz}, 2 \mathrm{H}$, pyrrolic), 9.52 (d, $J=4.5 \mathrm{~Hz}, 2 \mathrm{H}$, pyrrolic). MS (MALDI-TOF, $m / z$ ): [M] calcd for $\mathrm{C}_{112} \mathrm{H}_{142} \mathrm{~N}_{6} \mathrm{O}_{6} \mathrm{~S}_{2} \mathrm{Zn}, 1794.97$; found, 1794.97. IR ( $\mathrm{KBr}$ pellet, $\left.\mathrm{cm}^{-1}\right)$ : 3359(br), 2922(s), 2852(s), 2166(w), 2030(w), 1956(m), 1659(w), 1632(w), 1588(m), 1493(w), 1455(s), 1393(w), 1374(w), 1289(w), 1247(w), 1181(w), 1100(s), 995(m), 790(m), 717(w).

\section{Results and discussion}

\section{Design and syntheses}

As shown in Scheme 1, all the four porphyrins were designed on the basis of $\mathrm{D}-\pi-\mathrm{A}$ frameworks. 2-Diphenylaminothiophene was introduced as the electron donor, and the porphyrin cores were wrapped with four dodecoxyl chains at the phenyl orthopositions with the purpose of suppressing the dye aggregation and preventing the approach of the electrolyte to the $\mathrm{TiO}_{2}$ surface, and thus decreasing the $\mathrm{I}_{3}{ }^{-}$concentration in the vicinity of $\mathrm{TiO}_{2}$, resulting in the improved $V_{\mathrm{oc}}$ of the DSSCs. ${ }^{13 c}$ In addition, to further investigate the effect of the acceptors on the cell performance, various acceptors were employed. Thus, dyes YQ1-YQ4 were designed, and the synthetic routes are depicted in Scheme 2. The dibromoporphyrin $\mathbf{1}^{13 c}$ was used to react with various ethynyl derivatives through Sonogashira coupling reactions to afford the intermediates 2a-2d. 2-Diphenylaminothiophene was then attached to the meso-position via Stille coupling reactions in satisfactory yields. Finally, the target sensitizers were synthesized through hydrolysis or Knoevenagel condensation reactions. Consequently, dyes YQ1-YQ4 were successfully synthesized in acceptable yields and fully characterized with NMR and HRMS (Fig. S1-S24, ESI $\dagger$ ).

\section{Spectral properties}

Strong absorption characteristics are vital for efficient DSSC sensitizers. The UV-visible absorption spectra and steady-state fluorescence spectra of the dyes in THF are shown in Fig. 1, and the corresponding data are listed in Table 1.

YQ1-YQ4 exhibit typical porphyrin absorption characteristics, with an intense Soret band in the range of 400-500 nm and less intense $Q$ bands in the range of 550-720 $\mathrm{nm}$. The Soret band for YQ1 is centred at $446 \mathrm{~nm}$ with the molar absorption coefficient of $1.53 \times 10^{5} \mathrm{M}^{-1} \mathrm{~cm}^{-1}$, and the corresponding bands are red shifted to 447, 468 and $468 \mathrm{~nm}$ for YQ2, YQ3 and YQ4, respectively. Meanwhile, the molar absorption coefficients are decreased to $0.64 \times 10^{5}-0.83 \times 10^{5} \mathrm{M}^{-1} \mathrm{~cm}^{-1}$. Compared with YQ1, the Q bands for YQ2-YQ4 are also red shifted. These results indicate that YQ1 has stronger absorption in the short wavelength range. Whereas, YQ2-YQ4 have stronger absorption in the long wavelength range. In comparison with most reported porphyrin dyes with similar structures, ${ }^{16}$ all the four porphyrin dyes demonstrate obviously red-shifted absorption maxima and broadened Soret bands. For example, YQ1 shows similar Soret bands and an obvious red shift of the Q band in the long wavelength range, compared with the porphyrin dyes 

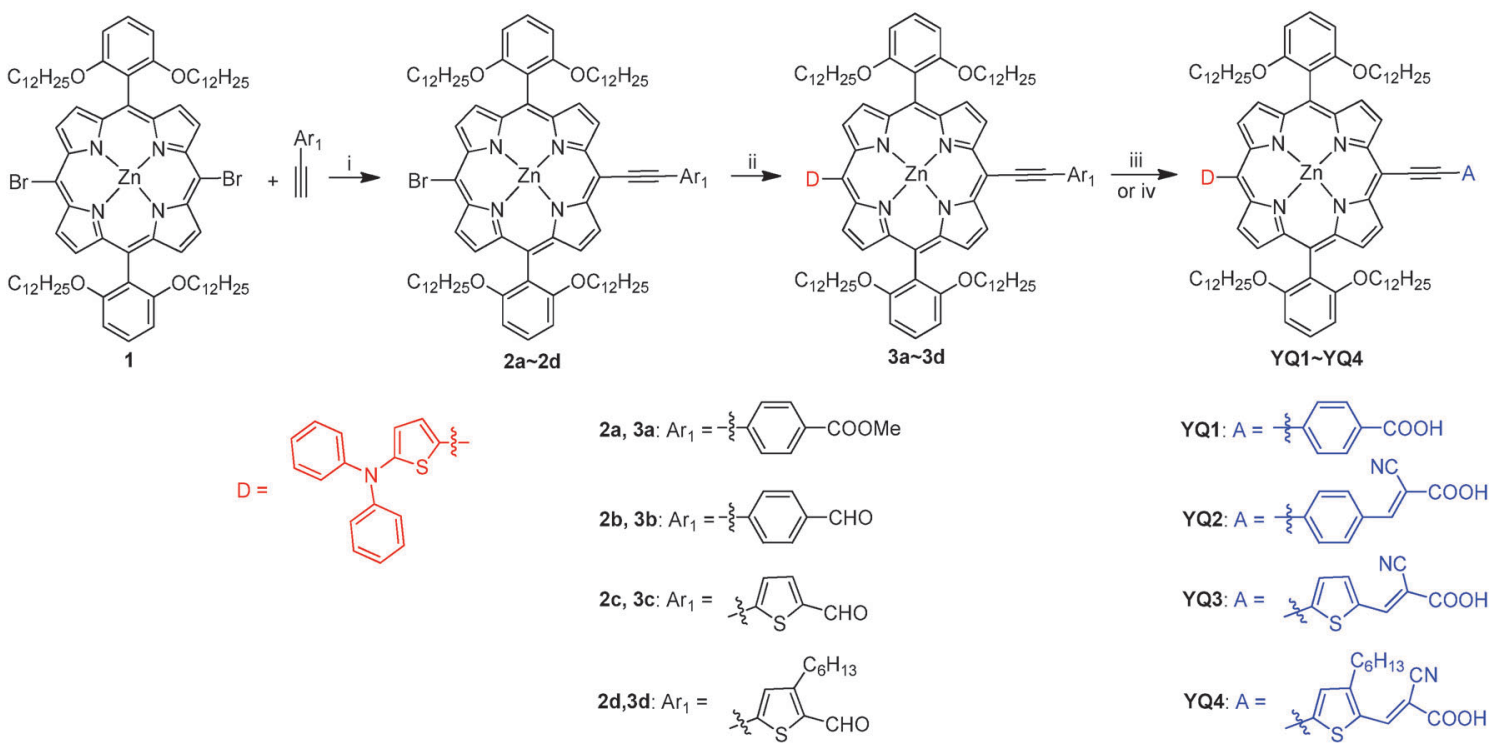

Scheme 2 The synthetic routes for dyes YQ1-YQ4. Reaction conditions: (i) $\mathrm{Pd}\left(\mathrm{PPh}_{3}\right)_{4}, \mathrm{Cul}, \mathrm{TEA}, \mathrm{THF}$, (ii) 2-diphenylamino-5-tributylstannylthiophene, $\mathrm{Pd}\left(\mathrm{PPh}_{3}\right)_{4}$, toluene, (iii) $\mathrm{LiOH} \cdot \mathrm{H}_{2} \mathrm{O}, \mathrm{THF}, \mathrm{H}_{2} \mathrm{O}$, (iv) cyanoacetic acid, piperidine, MeCN.
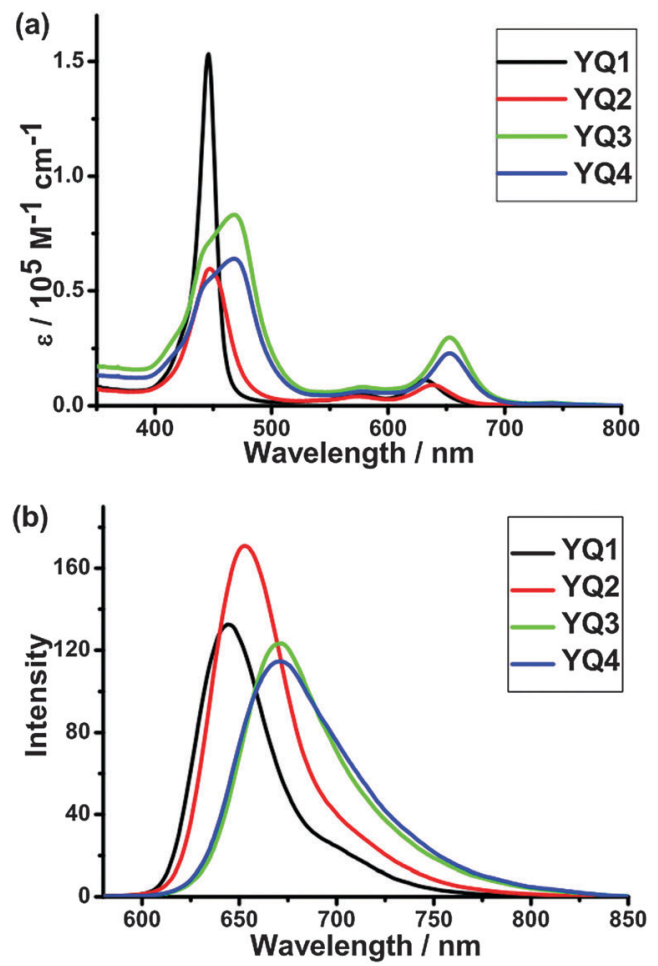

Fig. 1 (a) Absorption and (b) emission spectra of YQ1-YQ4 in THF.

CPZ, DPZ1 and DPZ2 (Scheme 3), ${ }^{16 a}$ which have similar structures containing a carbazole or a methoxyphenyl unit as the donor. Among the porphyrin dyes using 2-cyano-3-(5-ethynylthienyl) acrylic acid as the electron acceptor, YQ3 and YQ4 show $5 \mathrm{~nm}$ red shift of the Soret band compared to $\mathbf{L W 2} \mathbf{2}^{16 b}$ which contains $\mathrm{N}, \mathrm{N}$-dimethylaminophenyl unit as the electron donor. Compared with dyes T3P and HT3P which contain a triphenylamine unit as the donor, ${ }^{11 a, 16 c}$ YQ1-YQ4 show broadened Soret bands.
Table 1 Absorption and emission data of the porphyrin dyes

\begin{tabular}{lll}
\hline Dyes & Absorption $\lambda_{\max }{ }^{a} / \mathrm{nm}\left(\varepsilon / 10^{3} \mathrm{M}^{-1} \mathrm{~cm}^{-1}\right)$ & Emission $\lambda_{\max }{ }^{a} / \mathrm{nm}$ \\
\hline YQ1 & $446(153), 575(5.6), 632(11.2)$ & 644 \\
YQ2 & $447(59.7), 575(4.1), 637(9.1)$ & 653 \\
YQ3 & $468(83.2), 578(8.2), 653(30.0)$ & 673 \\
YQ4 & $468(64.0), 578(6.0), 653(23.0)$ & 671
\end{tabular}

${ }^{a}$ Absorption and emission data were measured in THF. Excitation wavelengths per nm: $446 \mathrm{~nm}$ (YQ1), $447 \mathrm{~nm}$ (YQ2), $468 \mathrm{~nm}$ (YQ3), 468 (YQ4).

The red shift of the absorption peaks and broadened absorption may be attributed to the stronger electron-donating ability of the 2-diphenylaminothiophene unit compared with the other donors. Thus, the introduction of 2-diphenylaminothiophene may be promising for the fabrication of efficient DSSCs. For the fluorescence spectra in THF (Fig. 1b), the emission wavelength variation trend is similar to that of the absorption bands.

To better elucidate the absorption properties of the porphyrin dyes in DSSC devices, the absorption spectra of the porphyrin dyes on $5 \mu \mathrm{m}$ transparent $\mathrm{TiO}_{2}$ films were measured and shown in Fig. 2. Compared with the corresponding solution spectra, both the Soret and $\mathrm{Q}$ bands of the porphyrin/ $/ \mathrm{TiO}_{2}$ films were considerably broadened. The absorption bands are obviously blue-shifted for YQ3 and YQ4, which may result from the deprotonation of the carboxylic acid group upon dye attachment to the $\mathrm{TiO}_{2}$ surface, ${ }^{17}$ and/or the $\mathrm{H}$-aggregation of the dye molecules on the $\mathrm{TiO}_{2}$ films. ${ }^{18}$

\section{Electrochemical behavior}

To evaluate the possibility of electron transfer from the excited dye molecules to the conduction band (CB) of $\mathrm{TiO}_{2}$, cyclic voltammetry measurements (Fig. 3) were performed on the porphyrin dyes adsorbed on the $\mathrm{TiO}_{2}$ films in $0.1 \mathrm{M}$ solution of tetra- $n$-butylammonium hexafluorophosphate in acetonitrile, and the corresponding data are listed in Table 2 . It can be 

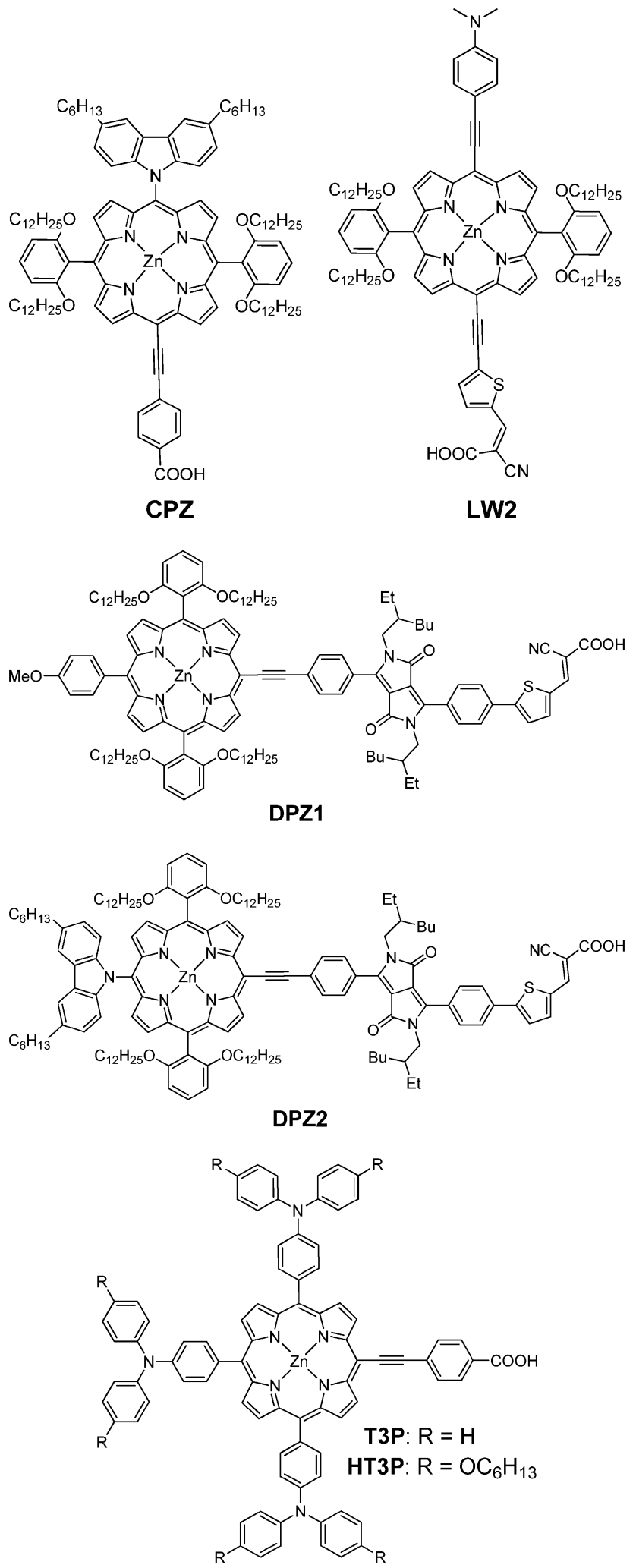

Scheme 3 Molecular structures of reported porphyrin dyes $\mathrm{CPZ}^{16 a}$ DPZ1, ${ }^{16 a}$ DPZ2, ${ }^{16 a}$ LW2, ${ }^{16 b}$ T3P, $^{11 a, 16 c}$ and HT3P. ${ }^{16 c}$

estimated from Fig. 3 that the first oxidation potentials for YQ1-YQ4 dyes are $0.69,0.69,0.67$ and $0.68 \mathrm{~V}$, respectively, versus the normal hydrogen electrode (NHE). The energy gaps

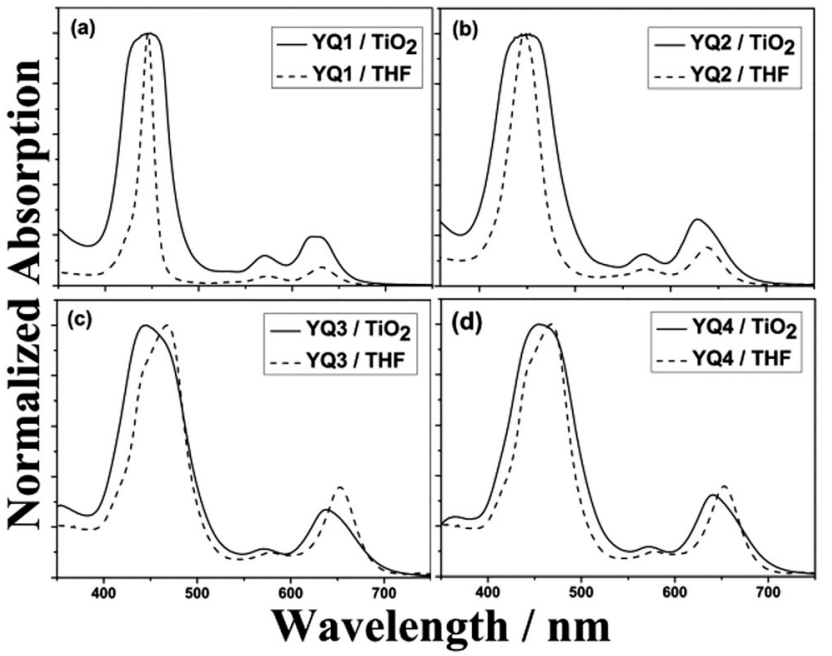

Fig. 2 Normalized UV-visible spectra of the porphyrins in THF and on the $\mathrm{TiO}_{2}$ films $(5 \mu \mathrm{m})$.

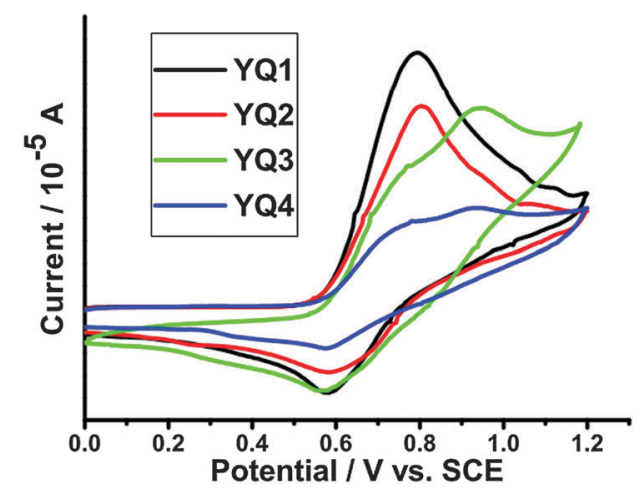

Fig. 3 The cyclic voltammetry curves of the dyes adsorbed to a nanocrystalline $\mathrm{TiO}_{2}$ film deposited on conducting FTO glass.

Table 2 Electrochemical properties of the porphyrin dyes

\begin{tabular}{llll}
\hline Dyes & $\mathrm{HOMO}^{a} / \mathrm{V}(v s . \mathrm{NHE})$ & $E_{0-0}{ }^{b} / \mathrm{V}$ & $\mathrm{LUMO}^{c} / \mathrm{V}(v s . \mathrm{NHE})$ \\
\hline YQ1 & 0.69 & 1.95 & -1.26 \\
YQ2 & 0.69 & 1.92 & -1.23 \\
YQ3 & 0.67 & 1.88 & -1.21 \\
YQ4 & 0.68 & 1.88 & -1.20
\end{tabular}

${ }^{a}$ HOMO levels were measured in acetonitrile using $0.1 \mathrm{M}$ tetrabutylammonium hexafluorophosphate $\left(\mathrm{TBAPF}_{6}\right.$ ) as the electrolyte (working electrode: $\mathrm{FTO} / \mathrm{TiO}_{2} /$ dye; reference electrode: SCE; calibrated with ferrocene/ferrocenium $\left(\mathrm{Fc} / \mathrm{Fc}^{+}\right)$as an external reference. Counter electrode: Pt). ${ }^{b} E_{0-0}$ was calculated from the wavelength at the intersection $\left(\lambda_{\text {inter }}\right)$ of normalized absorption and emission spectra with the equation $E_{0-0}=1240 / \lambda_{\text {inter }}{ }^{c}$ The LUMO was calculated from the equation of LUMO $=$ HOMO $-E_{0-0}$.

$E_{0-0}$ are determined to be $1.95,1.92,1.88$ and $1.88 \mathrm{~V}$ for YQ1, YQ2, YQ3 and YQ4, respectively, through the intersection of the normalized absorption and emission spectra. Thus, the LUMO levels of these dyes (YQ1-YQ4) are calculated to be -1.26 , $-1.23,-1.21$ and $-1.20 \mathrm{~V}$, respectively. The HOMO levels for these four dyes are almost identical, which can be attributed to 


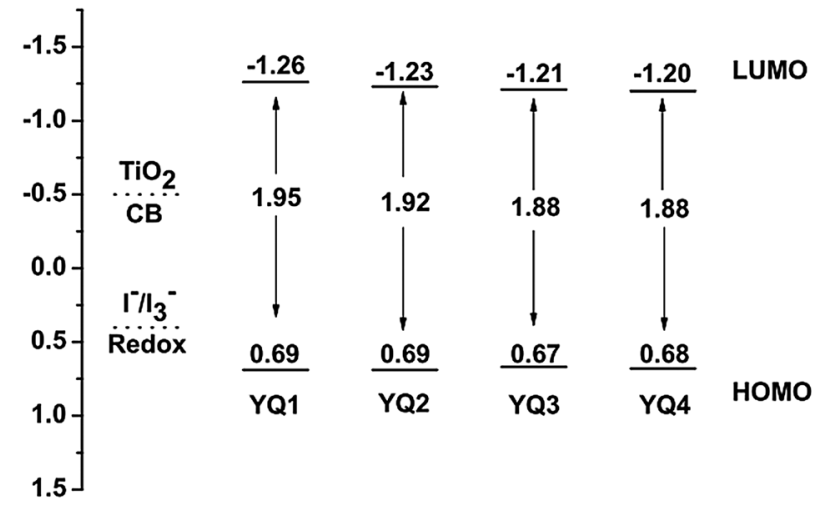

Fig. 4 Schematic energy-level diagram of YQ1-YQ4.

the similar electron-donating ability of the donors in the four dyes. On the other hand, the LUMO energy levels for YQ2, YQ3 and YQ4 are slightly lower than that of YQ1, which may be attributed to the difference in the acceptor moieties.

To guarantee efficient electron injection from the LUMO of the porphyrin dyes into the $\mathrm{CB}$ of $\mathrm{TiO}_{2}$, the LUMO levels must be higher than that of the conduction band edge of $\mathrm{TiO}_{2}$. And the HOMO levels of the sensitizers must be lower than the redox potential of the electrolyte $\mathrm{I}^{-} / \mathrm{I}_{3}{ }^{-}$couple to ensure efficient regeneration of the sensitizer cations following the photoinduced electron injection into the conduction band of $\mathrm{TiO}_{2}$. As shown in Fig. 4, the LUMO levels of these dyes are more negative than the $\mathrm{CB}$ of $\mathrm{TiO}_{2}(-0.5 \mathrm{~V} v s$. NHE), indicating that electron injection from the excited states of the dyes into the $\mathrm{CB}$ of $\mathrm{TiO}_{2}$ is energetically permitted. On the other hand, the HOMO levels of YQ1-YQ4 are more positive than the iodine/ iodide redox potential value ( $0.4 \mathrm{~V} v s$. NHE), indicating that the oxidized dyes formed upon electron injection into the $\mathrm{CB}$ of $\mathrm{TiO}_{2}$ thermodynamically could be regenerated by accepting electrons from the $\mathrm{I}^{-}$ions. ${ }^{19}$ The HOMO levels of the four porphyrin dyes are almost identical, and the LUMO level of YQ1 is slightly higher with respect to those of YQ2-YQ4, which results in a larger driving force for the electron injection process. Thus, it can be anticipated that YQ1 sensitized solar cells will demonstrate higher efficiency than those of the other porphyrin dyes. This is in agreement with the photovoltaic performance results (vide infra).

\section{Theoretical calculations}

To gain further insight into the electron distribution at the frontier molecular orbitals, we employed density functional theory (DFT) calculations to optimize the geometries of YQ1-YQ4. For the calculations, the long alkyl chains in these compounds were replaced by methyl groups to save computational time while preserving their steric effect. The hybrid B3LYP functional ${ }^{20}$ was used together with a mixed basis set, i.e., the Los Alamos effective core potential basis set (LANL2DZ) ${ }^{21}$ for zinc ions and the $6-31 \mathrm{G}^{*}$ basis set ${ }^{22}$ for the other atoms, as implemented by the Gaussian 09 program package. ${ }^{23}$ Fig. 5 shows the corresponding molecular orbitals. It is obvious that the HOMO orbitals of the dyes are delocalized through the 2-diphenylaminothiophene and the porphyrin frameworks while the LUMO orbitals are delocalized between the porphyrin frameworks and the anchoring carboxyl groups. Thus, the excitation of the electron from the HOMO to the LUMO can result in electron redistribution from the donor to the anchoring moiety and thus realize electron injection from the LUMO orbital to the conduction band of $\mathrm{TiO}_{2}$. Therefore, it may be concluded that YQ1-YQ4 are suitable for using as DSSC sensitizers.

\section{Photovoltaic performance}

Solar cells were fabricated using YQ1-YQ4 as the sensitizers. To evaluate the photovoltaic performance, the incident photon-toelectron conversion efficiency (IPCE) was checked as a function of incident wavelength (Fig. 6). Because of the strong absorption bands, these porphyrin dyes demonstrated moderate to high IPCE values in a large wavelength range of $400-800 \mathrm{~nm}$. For YQ1, a broad peak at around $450 \mathrm{~nm}$ and two well-separated peaks between 550 and $700 \mathrm{~nm}$ were observed, corresponding to the Soret and Q bands, respectively. For YQ2-YQ4, the IPCE spectra demonstrated similar characteristics. In good agreement with the absorption spectra, the onset wavelengths of photocurrent responses were red-shifted from $750 \mathrm{~nm}$ for YQ1 to
LUMO
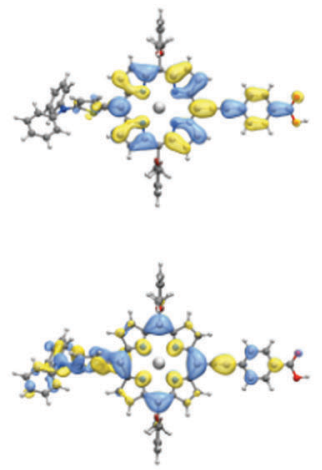

YQ1
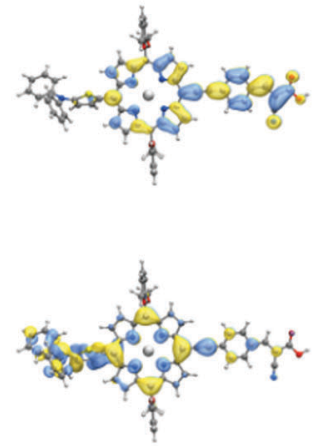

YQ2
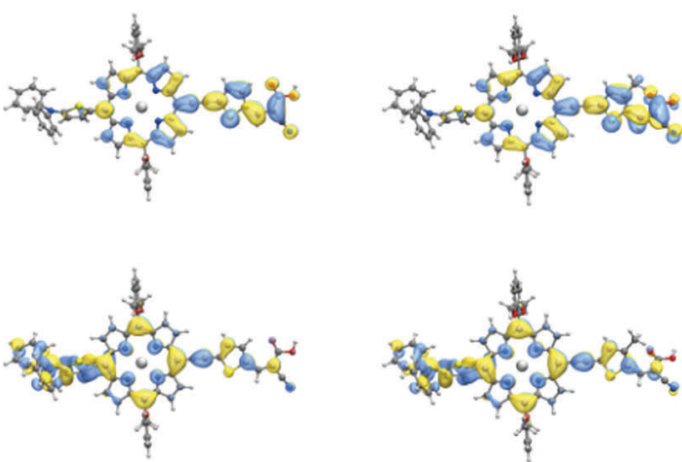

YQ3

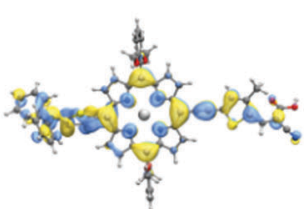

YQ4

Fig. 5 Frontier molecular orbital profiles of YQ1-YQ4 calculated by DFT. 


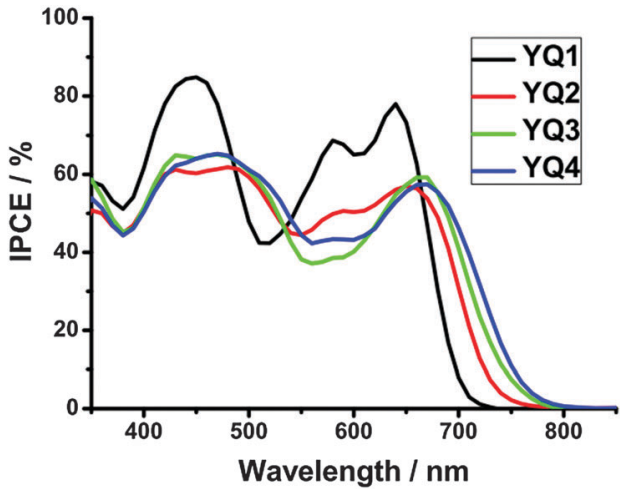

Fig. 6 IPCE action spectra of YQ1, YQ2, YQ3 and YQ4-based DSSCs.

$800 \mathrm{~nm}$ for YQ4, it is noteworthy that the high plateau of YQ1 (about $84.7 \%$ ) is much higher than the other three dyes (from $62.5 \%$ to $66.0 \%$ ). This may result in the highest current density for the cells based on YQ1 (vide infra) despite its relatively smaller IPCE values relative to YQ2-YQ4 in the NIR region. For YQ2-YQ4, their maximum IPCE values are almost identical, and their onset wavelength thresholds (Fig. 6) lie in the order of YQ2 < YQ3 < YQ4, which is in consistent with the relative magnitude sequence of $J_{\mathrm{sc}}$ as described below.

The current density-voltage $(J-V)$ curves of the DSSCs based on YQ1-YQ4 were measured under simulated AM1.5G irradiation $\left(100 \mathrm{~mW} \mathrm{~cm}^{-2}\right)$ and shown in Fig. 7, where $J_{\mathrm{sc}}, V_{\mathrm{oc}}, \mathrm{FF}$, and the power conversion efficiency $(\eta)$ can be obtained, and the corresponding data are listed in Table 3.

The overall power conversion efficiencies lie in the range of 4.23-6.01\%, exhibiting an order of YQ2 $\approx \mathbf{Y Q 3}<\mathrm{YQ4}<\mathrm{YQ1}$. As described above, YQ1 and YQ2-YQ4 contain the 4-ethynylbenzoic acid and the cyanoacrylic acid moieties as the acceptors, respectively. The DSSCs based on YQ1 exhibited the highest $\eta$ value of $6.01 \%$ $\left(J_{\mathrm{sc}}=14.27 \mathrm{~mA} \mathrm{~cm}^{-2}, V_{\mathrm{oc}}=0.68 \mathrm{~V}, \mathrm{FF}=0.62\right)$. And the efficiencies obtained for YQ2-YQ4 are lower than that for YQ1, lying in the range of $4.23-5.00 \%$. These observations may be ascribed to the floppy structures of YQ2-YQ4 induced by the cyanoacrylic acid moieties which provide free space for charge recombination. This observation is similar to the results reported by Yeh and Wang et $a l .{ }^{16 b, 24}$ And compared with YQ3, the attachment of a

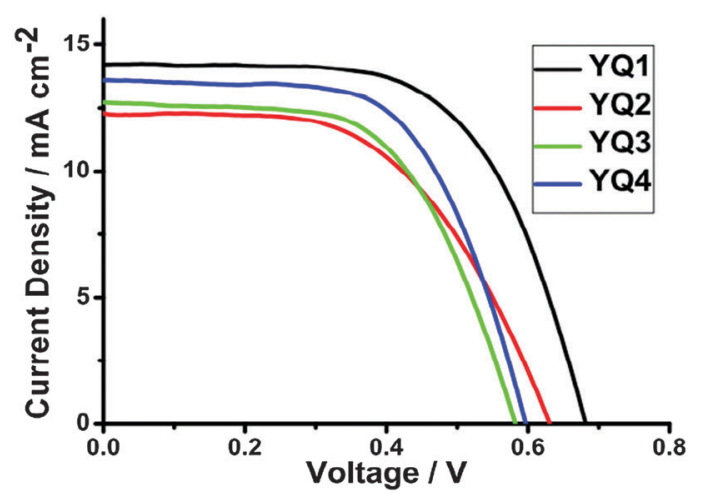

Fig. 7 Current-voltage characteristics of the DSSCs based on YQ1-YQ4.
Table 3 Photovoltaic parameters of porphyrin-based dye-sensitized solar cells under AM1.5 illumination (power $100 \mathrm{~mW} \mathrm{~cm}^{-2}$ ) with an active area of $0.25 \mathrm{~cm}^{2}$

\begin{tabular}{lclll}
\hline Dyes & $J_{\text {sc }} / \mathrm{mA} \mathrm{cm}^{-2}$ & $V_{\text {oc }} / \mathrm{V}$ & FF & $\eta(\%)$ \\
\hline YQ1 & 14.27 & 0.68 & 0.62 & 6.01 \\
YQ2 & 12.51 & 0.63 & 0.54 & 4.23 \\
YQ3 & 12.76 & 0.58 & 0.59 & 4.38 \\
YQ4 & 13.61 & 0.60 & 0.62 & 5.00 \\
CPZ $^{16 a}$ & 7.34 & 0.57 & 0.71 & 2.93 \\
DPZ1 $^{16 a}$ & 17.70 & 0.63 & 0.70 & 7.74 \\
DPZ2 $^{16 a}$ & 9.11 & 0.53 & 0.70 & 3.40 \\
LW2 $^{16 b}$ & 15.36 & 0.69 & 0.70 & 7.37 \\
T3P $^{11 a}$ & 12.38 & 0.57 & 0.58 & 4.10 \\
T3P $^{16 c}$ & 10.09 & 0.63 & 0.67 & 4.19 \\
HT3P $^{16 c}$ & 7.83 & 0.62 & 0.70 & 3.40 \\
\hline
\end{tabular}

hexyl group to the thienyl ring of YQ4 results in an improved voltage, which may be related to the suppression of the dye aggregation and the charge recombination processes. ${ }^{25}$ In comparison with similar porphyrin dyes CPZ, DPZ2, T3P and HT3P (Scheme 3) containing carbazole or triphenylamine as the donors, ${ }^{11 a, 16 a, c}$ the DSSCs based on YQ1 show higher efficiencies. This observation may be ascribed to the strong electron-donating ability of 2-diphenylaminothiophene which can obviously red-shift and broaden the absorption bands as described above, and thus broaden the IPCE spectrum and enhance the current density. On the other hand, the DSSCs based on DPZ1 ${ }^{16 a}$ show a higher efficiency of $7.74 \%$, which may be attributed to the presence of the diketopyrrolopyrrole fragment, which filled the absorption gap between the Soret band and the $\mathrm{Q}$ bands, thus a higher current density of $17.70 \mathrm{~mA} \mathrm{~cm}{ }^{-2}$ was obtained. LW2 ${ }^{16 b}$ also exhibits a higher efficiency of 7.37\% compared with those observed for YQ1-YQ4, which may be ascribed to the more red-shifted IPCE spectrum of LW2 in the near infrared region, resulting in a higher current density of $15.36 \mathrm{~mA} \mathrm{~cm}^{-2}$. Based on the above observations, it can be concluded that the introduction of 2-diphenylaminothiophene as the donor may be promising for the design of porphyrin-based efficient DSSC sensitizers, and the cell efficiencies may be further improved by further optimizing the structures and extending the absorption spectra. ${ }^{16}$

\section{Electrochemical impedance spectroscopy}

To further understand the electron transport and recombination processes for the DSSCs based on dyes YQ1-YQ4, the electrochemical impedance spectroscopy (EIS) was measured in the dark within a frequency range of $0.1 \mathrm{~Hz}$ to $100 \mathrm{kHz}$. The Nyquist and Bode plots for the sensitized cells are shown in Fig. 8. In general, a typical EIS spectrum of a DSSC exhibits three components in the order of increasing frequency, which can be assigned to the Nernst diffusion within the electrolyte (in the $\mathrm{MHz}$ range), the charge transfer at the tin oxide/electrolyte interface (in the $10 / 100 \mathrm{~Hz}$ range), and the redox reaction at the $\mathrm{Pt}$ counter electrode (in the $\mathrm{kHz}$ range), respectively. In some cases, only two of the components can be observed, because the Nernst diffusion part within the electrolyte is overlapped by the intermediate-frequency counterpart, which 

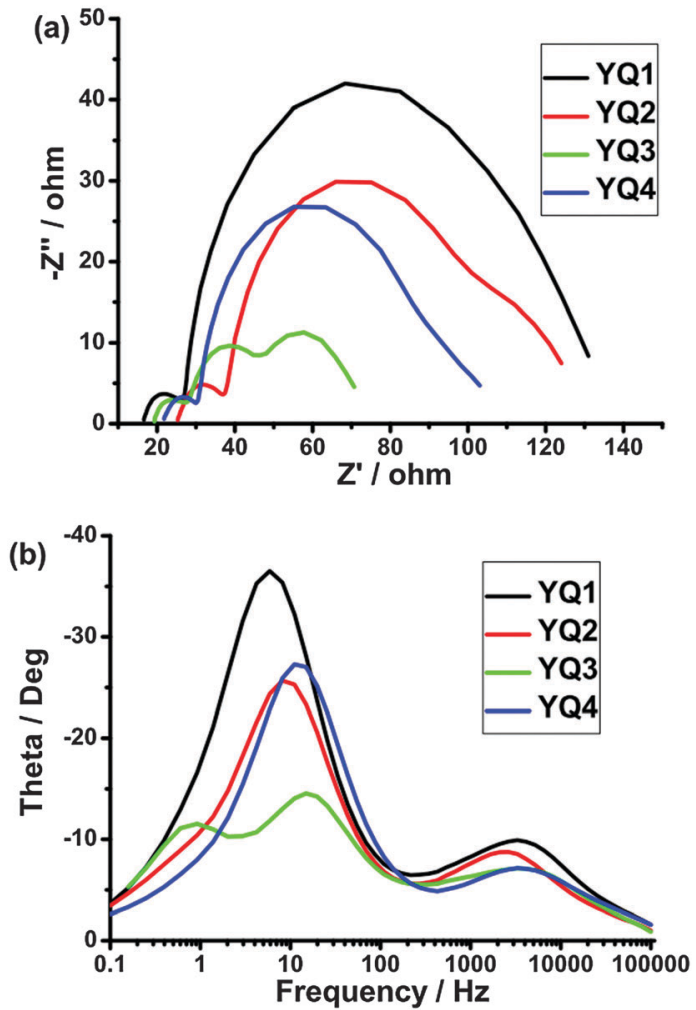

Fig. 8 Electrochemical impedance spectra of DSSCs based on porphyrin dyes under dark. (a) Nyquist plots; (b) Bode phase plots.

is indicative of fast electron transport and long electron lifetime in the $\mathrm{TiO}_{2}$ film. ${ }^{26}$ As shown in the EIS Nyquist plots (Fig. 8a), the radii of the middle semicircles lie in the order of YQ3 $<$ YQ4 < YQ2 < YQ1, indicating the sequence of charge transfer resistance. Thus, the sequence of charge recombination resistance at the surface lies in the order of YQ3 $<$ YQ4 $<$ YQ2 $<$ YQ1.

Fig. $8 \mathrm{~b}$ shows the EIS Bode plots, i.e., the phase angles of the impedance $v s$. the frequencies, for the DSSCs. As is well known, the characteristic frequency of the peak in the intermediate frequency region is related to the charge recombination rate, and its reciprocal is proportional to the electron lifetime. ${ }^{27}$ The peak maximum of the DSSC based on YQ1 is shifted to a lower frequency relative to the other three dyes, indicative of the longest electron lifetime, and the electron lifetime values derived from the curve fitting are 27.0, 19.6, 10.7 and $14.3 \mathrm{~ms}$, for YQ1, YQ2, YQ3 and YQ4, respectively. Thus, the longest electron lifetime observed for YQ1 indicates the effective suppression of the back reaction of the injected electron with the $\mathrm{I}_{3}{ }^{-}$in the electrolyte, resulting in the highest photovoltage. The EIS results are in good agreement with the photovoltaic performance (Fig. 7 and Table 3).

\section{Conclusions}

In summary, we synthesized porphyrin-based DSSC dyes YQ1-YQ4 with 2-diphenylaminothiophene attached at the meso-position as the electron donor. 4-Ethynylbenzoic acid and 2-cyanoacrylic acid with various aromatic groups were incorporated as the anchoring moieties into YQ1, and YQ2-YQ4, respectively. In comparison with most reported porphyrin dyes with similar structures, YQ1-YQ4 demonstrate obviously red-shifted absorption maxima and broadened Soret bands. YQ4 shows better photovoltaic performance compared with YQ2 and YQ3, which may be attributed to the suppression of the dye aggregation by the hexyl chain attached to the thienyl ring of YQ4. On the other hand, YQ2-YQ4 demonstrate lower efficiencies compared with YQ1, which may be ascribed to the floppy structures of the cyanoacrylic acid-based porphyrins that provide free space for charge recombination. As a result, the DSSCs based on YQ1 exhibited the highest efficiency of $6.01 \%$. This work demonstrates that the introduction of 2-diphenylaminothiophene into a porphyrin framework can obviously red-shift and broaden the absorption bands of the porphyrin dyes, resulting in high solar cell efficiencies. Hence, the introduction of 2-diphenylaminothiophene as the electron donor may be promising for the design of efficient porphyrin-based DSSC sensitizers.

\section{Acknowledgements}

This work was financially supported by NSFC (21072060, 91227201), the Oriental Scholarship, NCET-11-0638, the Fundamental Research Funds for the Central Universities (WK1013002), and SRFDP (20100074110015).

\section{Notes and references}

1 B. O'Regan and M. Grätzel, Nature, 1991, 353, 737.

2 (a) L. L. Li and E. W. G. Diau, Chem. Soc. Rev., 2013, 42, 291; (b) S. Zhang, X. Yang, Y. Numata and L. Y. Han, Energy Environ. Sci., 2013, 6, 1443.

3 Q. J. Yu, Y. H. Wang, Z. H. Yi, N. N. Zu, J. Zhang, M. Zhang and P. Wang, ACS Nano, 2010, 4, 6032.

4 (a) J. H. Delcamp, Y. Shi, J. Yum, T. Sajoto, E. Dell'Orto, S. Barlow, M. K. Nazeeruddin, S. R. Marder and M. Grätzel, Chem. - Eur. J., 2013, 19, 1819; (b) J. H. Delcamp, A. Yella, T. W. Holcombe, M. K. Nazeeruddin and M. Grätzel, Angew. Chem., Int. Ed., 2013, 52, 376; (c) Q. Li, J. Shi, H. Li, S. Li, C. Zhong, F. Guo, M. Peng, J. L. Hua, J. Qin and Z. Li, J. Mater. Chem., 2012, 22, 6689; (d) J. Liu, Y. Numata, C. J. Qin, A. Islam, X. D. Yang and L. Y. Han, Chem. Commun., 2013, 49, 7587; (e) Q. Y. Feng, X. W. Jia, G. Zhou and Z. S. Wang, Chem. Commun., 2013, 49, 7445; ( $f$ ) C. Chen, X. C. Yang, M. Cheng, F. G. Zhang, J. H. Zhao and L. C. Sun, RSC Adv., 2013, 3, 12688.

5 (a) K. Pei, Y. Wu, W. Wu, Q. Zhang, B. Chen, H. Tian and W. H. Zhu, Chem. - Eur. J., 2012, 18, 8190; (b) S. H. Aaron, B. K. Chandra, B. G. Chandra, R. S. Lindsey and D. S. Francis, ACS Appl. Mater. Interfaces, 2013, 5, 5314; (c) M. Katono, T. Bessho, M. Wielopolski, M. Marszalek, J. Moser, R. H. Baker, S. M. Zakeeruddin and M. Grätzel, J. Phys. Chem. C, 2012, 116, 16876; (d) J. Liu, X. Yang, J. Zhao and L. Sun, RSC Adv., 2013, 3, 15734; (e) X. Ren, S. Jiang, M. Cha, G. Zhou and Z. S. Wang, Chem. Mater., 2012, 
24, 3493; $(f)$ J. Shi, J. Chen, Z. Chai, H. Wang, R. Tang, K. Fan, M. Wu, H. Han, J. Qin, T. Peng, Q. Li and Z. Li, J. Mater. Chem., 2012, 22, 18830.

6 (a) B. Liu, W. H. Zhu, Q. Zhang, W. J. Wu, M. Xu, Z. J. Ning, Y. S. Xie and H. Tian, Chem. Commun., 2009, 1766; (b) W. Q. Li, Y. Z. Wu, X. Li, Y. S. Xie and W. H. Zhu, Energy Environ. Sci., 2011, 4, 1830.

7 J. Deisenhofer and J. R. Norris, The Photosynthetic Reaction, Academic Press, New York, 1993.

8 (a) S. H. Kang, I. T. Choi, M. S. Kang, Y. K. Eom, M. J. Ju, J. Y. Hong, H. S. Kang and H. K. Kim, J. Mater. Chem. A, 2013, 1, 3977; (b) J. Warnan, L. Favereau, F. Meslin, M. Severac, E. Blart, Y. Pellegrin, D. Jacquemin and F. Odobel, ChemSusChem, 2012, 5, 1568; (c) J. Luo, M. Xu, R. Li, K. Huang, C. Jiang, Q. Qi, W. Zeng, J. Zhang, C. Chi, P. Wang and J. S. Wu, J. Am. Chem. Soc., 2014, 136, 265.

9 (a) C. Lee, H. Lu, C. Lan, Y. Huang, Y. Liang, W. Yen, Y. Liu, Y. Lin, E. W. G. Diau and C. Y. Yeh, Chem. - Eur. J., 2009, 15, 1403; (b) J. Lu, X. Xu, Z. Li, K. Cao, J. Cui, Y. Zhang, Y. Shen, Y. Li, J. Zhu, S. Dai, W. Chen, Y. Cheng and M. Wang, Chem. - Asian J., 2013, 8, 956; (c) A. Yella, H. W. Lee, H. N. Tsao, C. Y. Yi, A. K. Chandiran, M. K. Nazeeruddin, E. W. G. Diau, C. Y. Yeh, S. M. Zakeeruddin and M. Grätzel, Science, 2011, 334, 629.

10 S. Mathew, A. Yella, P. Gao, R. H. Baker, B. F. E. Curchod, N. A. Astani, I. Tavernelli, U. Rothlisberger, M. K. Nazeeruddin and M. Grätzel, Nat. Chem., 2014, 6, 242.

11 (a) B. Liu, W. H. Zhu, Y. Q. Wang, W. J. Wu, X. Li, B. Chen, Y. T. Long and Y. S. Xie, J. Mater. Chem., 2012, 22, 7434; (b) Y. Q. Wang, X. Li, B. Liu, W. J. Wu, W. H. Zhu and Y. S. Xie, $R S C A d v ., 2013,3,14780$.

12 (a) R. Ambre, K. Chen, C. Yao, L. Luo, E. W. G. Diau and C. H. Hung, J. Phys. Chem. C, 2012, 116, 11907; (b) Y. Liu, N. Xiang, X. Feng, P. Shen, W. Zhou, C. Weng, B. Zhao and S. Tan, Chem. Commun., 2009, 2499.

13 (a) C. Y. Lee and J. T. Hupp, Langmuir, 2010, 26, 3760; (b) C. Y. Lee, C. X. She, N. C. Jeong and J. T. Hupp, Chem. Commun., 2010, 46, 6090; (c) C. L. Wang, C. M. Lan, S. H. Hong, Y. F. Wang, T. Y. Pan, C. W. Chang, H. H. Kuo, M. Y. Kuo, E. W. G. Diau and C. Y. Lin, Energy Environ. Sci., 2012, 5, 6933; (d) Y. C. Chang, C. L. Wang, T. Y. Pan, S. H. Hong, C. M. Lan, H. H. Kuo, C. F. Lo, H. Y. Hsu, C. Y. Lin and E. W. G. Diau, Chem. Commun., 2011, 47, 8910.

14 (a) M. Lee, M. S. Kang, M. Shin, J. Park, D. S. Chung, C. E. Park, S. Kwon and Y. Kim, J. Polym. Sci., Part A: Polym. Chem., 2010, 48, 3942; (b) J. L. Song, P. Amaladass, S. H. Wen, K. K. Pasunooti, A. Li, Y. L. Yu, X. Wang, W. Deng and X. W. Liu, New J. Chem., 2011, 35, 127.
15 S. Ito, T. N. Murakami, P. Comte, P. Liska, C. Grätzel, M. K. Nazeeruddin and M. Grätzel, Thin Solid Films, 2008, 516, 4613.

16 (a) L. Favereau, J. Warnan, F. B. Anne, Y. Pellegrin, E. Blart, D. Jacquemin and F. Odobel, J. Mater. Chem. A, 2013, 1, 7572; (b) J. Lu, X. Xu, K. Cao, J. Cui, Y. Zhang, Y. Shen, X. Shi, L. Liao, Y. Cheng and M. Wang, J. Mater. Chem. A, 2013, 1, 10008; (c) A. Aljarilla, J. N. Clifford, L. Pelleja, A. Moncho, S. Arrechea, P. Cruz, F. Langa and E. Palomares, J. Mater. Chem. A, 2013, 1, 13640.

17 (a) M. K. Nazeeruddin, P. Pechy, T. Renouard, S. M. Zakeeruddin, R. Humphry-Baker, P. Comte, P. Liska, C. Le, E. Costa, V. Shklover, L. Spiccia, G. B. Deacon, C. A. Bignozzi and M. Grätzel, J. Am. Chem. Soc., 2001, 123, 1613; (b) Z. S. Wang and H. Sugihara, Langmuir, 2006, 22, 9718.

18 E. G. McRae and M. Kasha, J. Chem. Phys., 1958, 28, 721. 19 (a) D. P. Hagberg, J. H. Yum, H. Lee, F. De Angelis, T. Marinado, K. M. Karlsson, R. Humphry-Baker, L. C. Sun, A. Hagfeldt, M. Grätzel and M. K. Nazeeruddin, J. Am. Chem. Soc., 2008, 130, 6259; (b) A. Hagfeldt and M. Grätzel, Chem. Rev., 1995, 95, 49.

20 (a) A. D. Becke, J. Chem. Phys., 1993, 98, 5648; (b) P. J. Stephens, F. J. Devlin, C. F. Chabalowski and M. J. Frisch, J. Phys. Chem., 1994, 98, 11623.

21 P. J. Hay and W. R. Wadt, J. Chem. Phys., 1985, 82, 270.

22 W. J. Hehre, R. Ditchfield and J. A. Pople, J. Chem. Phys., 1972, 56, 2257.

23 M. J. Frisch, G. W. Trucks, H. B. Schlegel, G. E. Scuseria, M. A. Robb, J. R. Cheeseman, G. Scalmani, V. Barone, B. Mennucci and G. A. Petersson, et al., Gaussian 09, Revision A.2, Gaussian, Inc., Wallingford, CT, 2009.

24 N. M. Reddy, T. Y. Pan, Y. C. Rajan, B. C. Guo, C. M. Lan, E. W. G. Diau and C. Y. Yeh, Phys. Chem. Chem. Phys., 2013, 15, 8409.

25 Y. Wu, M. Marszalek, S. M. Zakeeruddin, Q. Zhang, H. Tian, M. Grätzel and W. H. Zhu, Energy Environ. Sci., 2012, 5, 8261 .

26 (a) Q. Wang, J. E. Moser and M. Grätzel, J. Phys. Chem. B, 2005, 109, 14945; (b) F. Fabregat-Santiago, J. Bisquert, G. Garcia-Belmonte, G. Boschloo and A. Hagfeldt, Sol. Energy Mater. Sol. Cells, 2005, 87, 117; (c) D. B. Kuang, S. Uchida, R. Humphry-Baker, S. M. Zakeeruddin and M. Grätzel, Angew. Chem., Int. Ed., 2008, 47, 1923; (d) R. Kern, R. Sastrawan, J. Ferber, R. Stangl and J. Luther, Electrochim. Acta, 2002, 47, 4213.

27 (a) J. Bisquert, Phys. Chem. Chem. Phys., 2003, 5, 5360; (b) J. Bisquert, A. Zaban, M. Greenshtein and I. Mora-Sero, J. Am. Chem. Soc., 2004, 126, 13550. 